\title{
Comparative Study on Nutritional Components and Egg Quality of Bashang Long Tail Laying Hens in different Feeding Models
}

\author{
Li Chang ${ }^{1,2^{*}}$, Jiguo Sun ${ }^{1}$ and Xianglong $\mathrm{Li}^{3}$ \\ ${ }^{1}$ College of Animal Science and Technology, Agricultural University of Hebei Province, Baoding 071001, Hebei, P. R. China \\ ${ }^{2}$ Qinhuangdao Animal Disease Control Center, Qinhuangdao 066001, Hebei, P. R. China \\ ${ }^{3}$ Hebei Normal University of Science and Technology, Qinhuangdao 066004, Hebei, P. R. China \\ *For correspondence: $37837775 @ q q . c o m$
}

Received 30 November 2020; Accepted 12 January 2021; Published 16 April 2021

\begin{abstract}
In this research, we made a comprehensive study about the egg quality and nutrient factors of Bashang long-tailed chickens in different housing systems (in-cage and free-range). The results showed that: 1) there was no significant difference in egg weight, egg shape index, egg yolk weight, egg yolk color, egg yolk ratio, egg white ratio, and Hahn unit between free-range and cage $(P$ $>0.05)$. Protein weight, protein height, eggshell weight, eggshell color and eggshell ratio were significantly higher in the cage than in free-range $(P<0.05)$ and the differences in eggshell weight, eggshell color, and eggshell ratio were extremely significant $(P<0.01)$. However, the thickness and strength of eggshell in free-range breeding were significantly higher than those caged $(P<0.05) .2)$ The content of water and crude protein in the eggs of the caged Bashang long-tail chicken was significantly higher than that of the free-range chicken $(P<0.05)$. 3) The content of crude fat content of free-range was significantly higher than that of caged chickens $(P<0.05)$, but there was no significant difference in cholesterol and vitamin $\mathrm{A}$ content. 4) Zinc content of eggs of Bashang long-tail chickens of free-range was significantly higher than that of caged chickens $(P<0.05)$, but there was no significant difference in the content of calcium and phosphorus. So it's better than the caged chicken in the free-range feeding condition, and the free-range feeding is suitable for the production of Bashang long-tail chicken. This study could be used as a reference to improve egg quality in the future. (C) 2021 Friends Science Publishers
\end{abstract}

Keywords: Bashang long-tail chicken; Cage; Egg quality; Free-range; Nutritional components

\section{Introduction}

With the development of the national economy and the improvement of people's living standards, people's demand for egg consumption has shifted from quantity to quality, and more and more attention has been paid to the internal quality of eggs, and also begin to pay attention to the quality of native eggs, which is the quality of eggs produced by local chicken breeds (Chang et al. 2020). Bashang long-tail chicken is the only local poultry in Hebei Province to be included in the Chinese livestock and poultry genetic resources list (Tang 2011), which is an excellent genetic resource of local poultry breeds and belongs to egg-meat chicken breeds. It lives in the Hebei province of China, mainly in the Bashang region of Zhang Jiakou and Chengde City (Li et al. 2015; Peng et al. 2019), which is small, strong, active, flexible and mainly raised by grazing and supplemented with the appropriate amount. It has strong foraging ability in the wild, rough feed tolerance, cold resistance, disease resistance, delicious meat, and good egg production performance. The eggshell of Bashang long-tail chicken is thick, not easy to crack, dark brown, resistant to the storage and not susceptible to bacterial infection. The yolk is reddish yellow with a color depth of about 10 . It contains high fat. After cooking, its color, aroma and taste is much better than those of white or light yellow eggs. The protein is clear, transparent, sticky, and great taste.

A study comparing the impact of commercial when housing systems found that hen management and nutrition have significant impacts on the resulting egg physical quality (Karcher et al. 2015). Furthermore, the researcher (Jones et al. 2014) determined that eggs from the conventional cage, enriched colony cage, and cage-free aviary housing systems declined in egg quality at a similar rate during extended cold storage (Jones et al. 2018). To investigate the effect of feeding methods on the quality of Bashang long-tail chicken eggs, this experiment caged experiment of Bashang long-tail chicken, compared and analyzed the egg quality and nutrient composition of caged and free-range eggs, and revealed the characteristics of Bashang long-tail chicken eggs. The impact of the environment on the quality of the Bashang long-tail chicken eggs provides a theoretical basis by adopting appropriate feeding methods. Meanwhile, test data provides a reference 
for the production and utilization of Bashang long-tail chicken. It also provides data support for consumers to correctly understand the nutritional value of eggs, and at the same time provides a scientific basis for consumers to choose nutrients rationally and match the diet structure.

\section{Materials and Methods}

\section{Experiments}

Experimental materials: In the base group of the Bashang long-tail chicken breeding core group (Zhangjiakou Jingxingyuan Ecological Agriculture Co., Ltd.), 1000 chickens were raised to 42-day-old, and then 500 chickens were transferred to 12 farmers (Equivalent to 12 replicates) of 5 natural villages in Changliang Town, Guyuan County, Hebei Province. Each household raises according to the past free-range feeding model ( 2 birds $/ \mathrm{m}^{2}$, male and female groups), using local raw grain oatmeal as the main feed material and naturally stocking them in the farmer's house. The remaining 500 chickens continue to be semi-open chicken coops and three-dimensional three-story cages in the Bashang long-tail chicken breeding base of Zhangjiakou Jingxingyuan Ecological Agriculture Co., Ltd. Feeding, dry powder feed 3 times a day, free to eat, drink water, daylight $16 \mathrm{~h}$.

\section{Experimental methods}

A total of 400 fresh eggs (every 200 fresh eggs) were collected from free-range and caged Bashang long-tail chickens at the peak of egg production (280 days old), with a laying rate of 70-80\%. Two hundred eggs were randomly selected from each group and analyzed in the laboratory of Hebei Normal University of science and technology. The remaining 200 eggs (100 free-range eggs and 100 cage eggs) were sent to the Beijing Institute of Nutritional Resources for the determination and analysis of fatty acids, cholesterol, trace elements, and other nutrients of Bahang long-tail eggs.

\section{Determination items and methods of egg quality}

Egg quality was determined by egg weight (EW), egg shape index (ESI), eggshell color (ESC), eggshell strength (ESS), eggshell weight (ESW), yolk weight (YW), eggshell thickness (EST), protein height (ah), yolk color (YC), Haugh unit (HU) (Wang et al. 2012; He et al. 2017, 2019). The weight of the egg is weighed with an electronic scale (accuracy $0.01 \mathrm{~g}$ ); the egg shape index, that is, the ratio of the long diameter to the short diameter of the egg, is determined by a vernier caliper; the color of the egg shell is measured by a photoelectric reflection colorimeter; the strength of the egg shell is measured by the egg shell strength tester (EFR-01, purchased from Israel ORKA Technology Co., Ltd.); eggshell thickness is measured with an eggshell thickness tester (ESTG-1, purchased from Israel ORKA Technology Co., Ltd.); protein height, force of egg beater or watch glass edge Knock the egg, put your hand close to the glass plate, carefully pour the egg content down on the crack on the horizontal glass plate, choose between 2 points between the edge of the yolk and the edge of the concentrated protein (Zhou et al. 2012); egg weight and egg yolk reuse separation Separate the egg yolk and the protein, and use the filter paper to dry the protein on the surface of the egg yolk. Do not damage the egg yolk membrane. Weigh them separately with an electronic balance; the egg yolk color, Hastelloy unit multi-function egg quality tester (model EA- 01, purchased from Israel ORKA Technology Co., Ltd.).

Nutritional chemical indicators include trace elements such as water, crude protein, crude fat, cholesterol, vitamin A, zinc, and selenium. After the egg is broken, separate the egg white and yolk in a petri dish, weigh the egg white and yolk separately and add the total weight of the petri dish, and place the petri dish in a constant temperature drying box at $50^{\circ} \mathrm{C} \sim 53^{\circ} \mathrm{C}$ overnight (Woollard et al. 2016), Weighing, the difference is even water content (Chun 2016). After the moisture determination, the air-dried samples were crushed to prepare the standards, and the measurement standards were based on: moisture "GB/T 5009.3-2016", crude protein "GB/T 5009.5-2016", crude fat "GB/T 5009.6-2016", cholesterol "GB/T" 37077-2018", vitamin A "GB/T 5009.82-2016", zinc "GB/T 5009.14-2017", selenium "GB/T 5009.93-2017" (Zhao et al. 2015).

\section{Results}

\section{The effect of different feeding models on egg quality}

From Table 1, it can be seen that Bashang long-tail chicken with different feeding models have no significant difference on the egg weight, egg shape index, egg yolk weight, egg yolk color, egg yolk ratio, protein ratio, and Haugh unit. The protein weight and protein height are higher (1.6 and $26.43 \%)$ in the cage group than in the free-range group $(P<$ $0.05)$. In free-range conditions, egg thickness and eggshell strength were 8 and $30.07 \%$ lower than in caged, respectively $(P<0.05)$. But, shell weight, eggshell color, and eggshell ratio was $14.78,21.2$ and $12.52 \%$ lower than caged chickens, respectively, the difference was extremely significant $(P<0.01)$.

\section{The effect of different feeding models on nutrients}

Comparing the nutrient composition of Bashang long-tail chicken eggs of different models, the results showed that the contents of crude protein, elemental selenium and iron in cage-raised eggs were significantly higher than that in freerange eggs $(P<0.01)$; The content of fat and elemental zinc were significantly lower than that of free-range eggs, but the moisture content was significantly higher than that of 
Table 1: Comparison on egg quality between locality layer fed with different feed model

\begin{tabular}{llll}
\hline Items & Cage & Free-range & $P$-value \\
\hline Egg weight $(\mathrm{g})$ & $49.37 \pm 5.31$ & $48.40 \pm 7.13$ & 0.750 \\
Egg shape index $(\%)$ & $1.328 \pm 0.04$ & $1.331 \pm 0.06$ & 0.805 \\
Eggshell weight (g) & $5.989 \pm 0.58$ & $5.218 \pm 0.73$ & 0.002 \\
Eggshell color (scale) & $32.0 \pm 5.65$ & $26.4 \pm 5.14$ & 0.001 \\
Eggshell thickness(mm) & $0.25 \pm 0.04$ & $0.27 \pm 0.03$ & $<0.05$ \\
Eggshell strength (pa) & $4.41 \pm 0.68$ & $5.736 \pm 0.685$ & 0.007 \\
Yolk weight (g) & $15.23 \pm 2.23$ & $15.483 \pm 2.99$ & 0.350 \\
Yolk color (scale) & $9.33 \pm 0.82$ & $9.95 \pm 1.19$ & 0.250 \\
Protein weight (g) & $28.15 \pm 3.76$ & $27.699 \pm 4.49$ & 0.045 \\
Protein height (mm) & $2.87 \pm 0.54$ & $2.27 \pm 0.60$ & 0.031 \\
Eggshell ratio (\%) & $12.13 \pm 1.73$ & $10.78 \pm 3.045$ & 0.001 \\
Yolk ratio (\%) & $30.85 \pm 1.50$ & $31.99 \pm 3.03$ & 0.428 \\
Albumen ratio (\%) & $57.02 \pm 1.96$ & $57.23 \pm 3.06$ & 0.876 \\
Haugh unit (Ha) & $50.87 \pm 9.34$ & $42.02 \pm 12.35$ & 0.299 \\
\hline Notes: & \multicolumn{3}{l}{} \\
If $P<0.01$, it means that the data of the two groups is very significantly different \\
If $0.01<P<0.05$, the data of the two groups is significantly different \\
If $P>0.05$, it means that there is no significant difference between the two groups
\end{tabular}

free-range eggs $(P<0.05)$; the differences in the contents of cholesterol, vitamin A, elemental calcium and phosphorus in cages and free-range eggs were not significant $(P>0.05)$; the differences in the contents of Se and Fe were very significant $(P<0.01)$.

\section{Discussion}

Eggshell quality is one of the important traits in the breeding of laying hens. It not only affects the hatching rate of breeding eggs but also is related to the preservation time of eggs and the rate of circulation damage (Liu et al. 2017; Ji et al. 2018). Eggshell weight, eggshell thickness, and eggshell strength is important parameters for measuring eggshell quality (Yang et al. 2015; Lv et al. 2017). In this experiment, the eggshell weight of Bashang long-tail chicken eggs of free-range is significantly lower than that of caged $(P<0.05)$, but the eggshell thickness and eggshell strength are significantly higher than those of caged Bashang long-tail chickens $(P<0.05)$ (Jones et al. 2002) and other studies show that the higher the strength of eggshell, the lower the breakage rate of eggs during transportation. The increase in the thickness of the eggshell effectively prevents pathogens such as bacteria from entering the egg through the eggshell holes, which is conducive to the preservation of the egg. Therefore, from the evaluation of eggshell quality, the free-range chicken eggs in this study are more beneficial to the storage, transportation, and preservation of eggs than caged eggs. Egg shape index is one of the important indicators to evaluate egg quality, and an appropriate egg shape index can reduce the occurrence of egg cracking and breakage. In this experiment, there was no significant difference in the egg shape index of Bashang long-tail chicken under different feeding methods, which was consistent with the theory of breed-related that egg shape depended on the structure of oviduct isthmus and the physiological state of fallopian tube wall studied by (Huang et al. 2019); It is consistent with the research of (Feng 2016) that the physical traits of eggs are greatly influenced by heredity.

The egg yolk is an important part of egg nutrition, which concentrates most of the egg nutrition. The proportion of egg yolk determines the quality of an egg (Wang et al. 2017). This study showed that the yolk weight, yolk color, and yolk ratio of free-range eggs are slightly higher than those of caged eggs, but there is no significant difference, indicating that the nutritional quality of freerange eggs is more abundant than that of caged eggs.

Haugh units (HU) and protein height are important indicators for measuring egg freshness, egg quality grading, and international egg quality testing. The egg quality grading standard given by the United States Department of Agriculture is that HU greater than 72 is a special grade, between 60 and 72 is an A grade and between 30 and 60 is a grade $\mathrm{B}$. With the prolonged storage time, due to protein hydrolysis, the protein concentration becomes thinner, the protein height decreases and HU becomes smaller. Higher the protein content, larger the $\mathrm{HU}$ and freshness of the egg. In this experiment, the protein quality of cage-raised and free-range chickens was all excellent. Due to intensive feeding management of caged chickens, the quality of eggs is uniform, while the quality of free-range eggs is uniform. In this experiment, the $\mathrm{HU}$ of Bashang long-tail chicken eggs on caged and free-range are both Grade B, and the difference between free-range and cage-raised is not significant. However, protein weight and protein height of caged eggs were significantly higher than those of freerange eggs. This is because water is the main component of egg whites and is closely related to the uninterrupted water supply in cages.

Cholesterol is an essential substance for human life activities and an important raw material for the synthesis of bile acid and vitamin $\mathrm{D}$, etc. however, high blood cholesterol content can cause diseases such as hypertension, atherosclerosis, coronary heart disease, and stroke. Egg yolk contains a large amount of cholesterol, which is the main source of exogenous cholesterol intake (Ge et al. 2017). In the understanding of cholesterol, the public has two distinct and one-sided views. One view believes that cholesterol is extremely harmful and cannot be eaten. Another view believes that eating cholesterol in moderation is not only harmless but also beneficial to health. However, under the current human nutritional conditions, it is not insufficient cholesterol intake, but access, people prefer low cholesterol food. As can be seen from Table 2, the Bashang long-tail chicken eggs in free are $6.82 \%$ lower than that of caged chicken, but the difference was not significant, which also proved the advantages of free-range.

The taste of eggs is closely related to their crude fat content and the higher the crude fat content, the stronger the aroma of eggs (Guo et al. 2007). To sum up, the fat content of free-range eggs is significantly higher than that of caged eggs $(P<0.05)$; the crude protein and water content are 
Table 2: Comparison on egg nutrients between locality layer fed with different feed model

\begin{tabular}{llll}
\hline Items & Cage & Free-range & $P$-value \\
\hline Moisture/\% & $74.28 \pm 0.62$ & $73.24 \pm 0.92$ & 0.026 \\
Crude protein/\% & $13.15 \pm 0.29$ & $12.37 \pm 0.53$ & 0.005 \\
$\mathrm{EE} / \%$ & $9.72 \pm 0.67$ & $10.87 \pm 0.85$ & 0.012 \\
$\mathrm{Cholesterol} /(\mathrm{mg} / 100 \mathrm{~g})$ & $419.4 \pm 41.8$ & $290.8 \pm 150.2$ & 0.129 \\
$\mathrm{Vitamin} \mathrm{A} /(\mathrm{mg} / 100 \mathrm{~g})$ & $0.22 \pm 0.02$ & $0.183 \pm 0.058$ & 0.223 \\
$\mathrm{Ca}(\mathrm{mg} / \mathrm{kg})$ & $307.87 \pm 31.32$ & $310.010 \pm 12.108$ & 0.688 \\
$\mathrm{P}(\mathrm{mg} / \mathrm{kg})$ & $95.05 \pm 5.280$ & $95.890 \pm 9.021$ & 0.793 \\
$\mathrm{Zn}(\mathrm{mg} / \mathrm{kg})$ & $11.040 \pm 4.72$ & $16.880 \pm 1.300$ & 0.042 \\
$\mathrm{Se}(\mathrm{mg} / \mathrm{kg})$ & $1.989 \pm 0.92$ & $0.091 \pm 0.013$ & 0.000 \\
$\mathrm{Fe}(\mathrm{mg} / \mathrm{kg})$ & $19.35 \pm 8.45$ & $2.886 \pm 0.169$ & 0.000 \\
\hline
\end{tabular}

If $P<0.01$, it means that the data of the two groups is very significantly different If $0.01<P<0.05$, the data of the two groups is significantly different

If $P>0.05$, it means that there is no significant difference between the two groups

significantly lower than those of caged eggs $(P<0.05)$ and the difference of crude protein is very significant $(P<0.01)$. This result which consistent with the studies of (Anderson 2011) and (Li et al. 2013) that the fat content of free-range eggs is significantly higher than that of caged eggs, but the water content was lower.

Vitamin A in eggs, which is commonly found in egg yolks, is also known as retinol, which is an important element in maintaining vision and is one of the most common micronutrients about immunity (Yin 2009; Ginzberg et al. 2000). From Table 2, it can be seen that the content of vitamin A in free-range chicken eggs was slightly lower than that of in caged eggs, which also indicated that the content of vitamin A was related to the way of feeding. All egg quality criteria were not significantly affected by dietary vitamin A except albumin percentage and Haugh units, since Haugh unit score was gradually increased with increasing vitamin A level (Zhao et al. 2005). Calcium, iron, and zinc are indispensable trace elements. Zinc is an important traced element in the growth and development of young children. It is the key to the growth of human brain cells, and enhances the body's immune function. Elemental selenium has antioxidant properties, can enhance the body's immunity, regulate the absorption of other trace elements, and prevent cancer. Therefore, the content of selenium in eggs is of great significance to the health of the human diet. The content of calcium and phosphorus is slightly higher than that caged of eggs, but the difference is not significant. The level of zinc can improve egg production indices and HU score, so the content of zinc is significantly higher than that caged of eggs; while the content of selenium and iron is significantly lower than that of caged eggs.

\section{Conclusion}

Poultry is relatively sensitive to the environment, so it is very important to provide a good environment that is conducive to the production of laying hens. Healthy farming is main stream today. Feeding methods of laying hens are roughly divided into the cage and free-range breeding. Cage breeding is a relatively common breeding mode, suitable for large-scale breeding with all-in and all-out, good hygienic conditions and strong controllability of egg quality, which guarantees a high egg production rate and egg product pass rate. Free-range breeding is mainly a small-scale group. Chickens eat freely, breed freely, and lay eggs freely. They have a large active space, little water pollution, and no feed additives. Under this model, the chicken is delicious, the egg has high nutritional value, and the flavor has a unique aroma.

People say that domestic firewood eggs have a strong fragrance and rich nutrition (El-Hack et al. 2017). This test shows that free-range eggs were better than cage eggs in shell thickness, yolk color, phospholipid content, and lower cholesterol content in egg yolk. The contents of crude fat, element iron, and zinc in free-range eggs were significantly higher than those in caged eggs, while the contents of crude protein, protein height, water and element selenium in freerange eggs were significantly lower than those in caged eggs. This is consistent with the studies of Zhao Chao and Yin Ruoxin, that free-range chickens can produce eggs with better yolk color, higher phospholipid content and lower yolk biliary solids content than caged chickens.

Our study was the first to compare the egg quality and nutrient composition of bashang long-tail chicken raised in a cage and free-range. In this paper, we found that the nutritional value of Bashang long-tail chicken eggs under free-range was higher than that of caged eggs.

\section{Acknowledgments}

This work was supported by Innovation Team Projects of Layer and Broiler in Modern Agricultural Industry Technology System of Hebei Province (HBCT2018150201, HBCT2013090206), Science and Technology Plan Project of Qinhuangdao City (201703A034) and College Innovation Team Leader Training Program of Hebei Province (LJRC004).

\section{Author Contributions}

Li Chang: Planning of study, standardization and execution of lab protocols, collection and analysis of samples from experimental animals, analysis of data and write up of manuscript, Jiguo Sun: Planning of study, analysis of data and write up of manuscript, Xianglong Li: Planning and execution of study, analysis of data and write up of manuscript.

\section{Conflict of Interest}

We declare that we have no conflict of interest.

\section{Data Availability}

All data, models, and code generated or used during the 
study appear in the submitted article.

\section{Ethics Approval}

All studies involving animals were reviewed and approved by the Institutional Animal Care and Use Committee of Hebei Normal University of Science and Technology, China. Procedures were performed in accordance with the Regulations for the Administration of Affairs Concerning Experimental Animals (The State Council of the People's Republic of China, 2011). Animals were humanely sacrificed as necessary to ameliorate suffering.

\section{References}

Anderson KE (2011). Comparison of fatty acid, cholesterol, and vitamin A and $\mathrm{E}$ composition in eggs from hens housed in conventional cage and range production facilities. Poult Sci 90:1600-1608

Chang L, XL Li, JG Sun (2020). The relationship between the expression of different genes and their polymorphism and egg laying traits in ovary of Bashang long tailed chicken and Hailan brown layer. Rev Cienfac Cienc Vet 30:542-551

Chun WM (2016). Comparative study of laying performance and egg quality of three hens breeds on cage and cage-free housing system. Sich Agric 2016:33-38

El Hack MEA, K Mahrose, AA Askar, M Alagawany, M Arif, M Saeed, F Abbasi, RN Soomro, FA Siyal, MT Chaudhary (2017). Single and combined impacts of vitamin a and selenium in diet on productive performance, egg quality, and some blood parameters of laying hens during hot season. Biol Trace Elem Res 177:169-179

Feng J (2016). Comparative study on egg quality of three chicken breeds. Anim Husb Feed Sci 37:12-14

Ge XK, M Li, KJ Ning (2017). Comparison of egg quality and nutritional component of deep fried chicken, native chicken and highland brown chicken. Heilongj Anim Sci Vet Med 10:58-60

Ginzberg A, M Cohen, UA Sod-Moriah, S Shany, A Rosenshtrauch, S Arad (2000). Chickens fed with biomass of the red microalga Porphyridium spp. Have reduced blood cholesterol level and modified fatty acid composition in egg yolk. J Appl Phycol 12:325-330

Guo CY, HM Yang, ZY Wang, Ly Yan (2007). Comparative study on the quality of different egg varieties. Poult Sci 2:12-14

He Y, L Chang, XM Guan, LY Geng, CX Lu, XL Li (2019). Comparison of nutritional components and egg quality between Bashang long tail laying hens and hy-line brown laying hens in cage. Chin J Anim Nutr 31:3535-3542

He Y, LY Geng, XL Li, XM Guan, CX Lu, YD Peng (2017). Comparison on egg quality and nutrient composition of eggs between Bashang long-tail and hy-line brown chicken in free range. Chin Poult 39:32-35

Huang YK, M Zhang, PK Yang, SC Ma, ZB Han, XL Wang, JY Fan, J Liu (2019). An analysis of the differences in egg quality in different breeder flocks. Mod Anim Husb 3:1-5
Ji XF, H Yang, XF Ji (2018). Effects of cage and free range mode on egg quality and primary nutrient components in Xianju chicken. Chin Poult 40:31-34

Jones DR, DM Karcher, P Regmi, CO Robison, RK Gast (2018). Hen genetic strain and extended cold storage influence on physical egg quality from cage-free aviary housing system. Poult Sci 97:23472355

Jones DR, DM Karcher, Z Abdo (2014). Effect of a commercial housing system on egg quality during extended storage. Poult Sci 93:1282-1288

Jones DR, KE Anderson, PA Curtis, EK Anderson (2002). Microbial contamination in inoculated shell eggs; Effects of layer strain and hen age. Poult Sci 81:715-720

Karcher DM, DR Jones, Z Abdo, Y Zhao, TA Shepherd, H Xin (2015). Impact of commercial housing systems and nutrient and energy intake on laying hen performance and egg quality parameters. Poult Sci 94:485-501

Li WN, ZR Zhang, FS Zhong, HY Wu, HB Cai, BH Liu (2013). Comparative study on the effects of different breeding modes on egg quality and nutritional components. J Jiay Univ 31:61-64

Li XH, XL Li, CX Lu, J Li (2015). The correlative and regressive analysis on body weight and size of Bashang long-tail chickens. Gansu Anim Husb Vet 45:42-45

Liu SZ, QY Wu, XM Cao (2017). Comparative analysis of egg quality of four breeds in Wenzhou. Heilongj Anim Sci Vet Med 2:73-75

Lv L, Y Li, MJ Jing, MD Ma, LA Li (2017). Comparative study on the egg qualities of ordinary eggs. Native Eggs and Dark Eggs. Acta Ecol Anim Domast 38:38-41

Peng YD, L Chang, YQ Wang, RN Lu, ZY Hu (2019). Genome-wide differential expression of long noncoding RNAs and mRNAs in ovarian follicles of two different chicken breeds. Genomics 111:1395-1403

Tang GC (2011). Chinese Livestock and Poultry Genetic Resources Records: Poultry Records. Agricultural Press, Beijing China

Wang KH, TC Dou, L Qu, J Guo, J Hong (2012). Comparison and analysis for egg quality of seven breeds of layer. Chin Poult 34:23-27

Wang LW, SX Chen, YJ Guo, CM Bai, JP Zhang, SM Yang, YL Shi (2017). Comparison and analysis of egg quality in different culture models. Poult Sci 12:11-14

Woollard DC, A Bensch, H Indyk, A McMahon (2016). Determination of vitamin $\mathrm{A}$ and vitamin $\mathrm{E}$ esters in infant formulae and fortified milk powders by HPLC: Use of internal standardization. Food Chem 197:457-465

Yang Y, BS Sun, Y Sun, YJ Lu, YX Yang, JH Li (2015). Effects of stocking density and supplementary feeding on egg quality of Alfalfa in jujube forest. Acta Zool Sin 369:72-76

Yin RX (2009). Analysis of factors affecting egg quality. Poult Sci 9:1-21

Zhao C, ZL Gu, J Tong, J Huang, YL Dong (2005). Study on the effect of feeding methods on egg quality. Chin Poult 9:108-110

Zhao PJ, BC Zhang, XH Gu, L Chen, LX Fan, JS Mao (2015). Determination of nutrient elements in different varieties of poultry eggs. Anim Husb Feed Sci 36:27-28

Zhou HQ, Q Zhu, G Shu, Y Zhang, XL Zhao (2012). Analysis and comparison of egg and meat quality of egg and meat in Erlang mountain area under free and cage conditions. Anim Husb Vet Med 44:39-40 